\title{
Crystal structure of the conserved domain of the DC lysosomal associated membrane protein: implications for the lysosomal glycocalyx
}

\author{
Sonja Wilke ${ }^{\dagger}$, Joern Krausze ${ }^{\dagger}$ and Konrad Büssow ${ }^{*}$
}

\begin{abstract}
Background: The family of lysosome-associated membrane proteins (LAMP) comprises the multifunctional, ubiquitous LAMP-1 and LAMP-2, and the cell type-specific proteins DC-LAMP (LAMP-3), BAD-LAMP (UNC-46, C20orf103) and macrosialin (CD68). LAMPs have been implicated in a multitude of cellular processes, including phagocytosis, autophagy, lipid transport and aging. LAMP-2 isoform A acts as a receptor in chaperone-mediated autophagy. LAMP-2 deficiency causes the fatal Danon disease. The abundant proteins LAMP-1 and LAMP-2 are major constituents of the glycoconjugate coat present on the inside of the lysosomal membrane, the 'lysosomal glycocalyx'. The LAMP family is characterized by a conserved domain of 150 to 200 amino acids with two disulfide bonds.

Results: The crystal structure of the conserved domain of human DC-LAMP was solved. It is the first highresolution structure of a heavily glycosylated lysosomal membrane protein. The structure represents a novel $\beta$-prism fold formed by two $\beta$-sheets bent by $\beta$-bulges and connected by a disulfide bond. Flexible loops and a hydrophobic pocket represent possible sites of molecular interaction. Computational models of the glycosylated luminal regions of LAMP-1 and LAMP-2 indicate that the proteins adopt a compact conformation in close proximity to the lysosomal membrane. The models correspond to the thickness of the lysosomal glycoprotein coat of only 5 to $12 \mathrm{~nm}$, according to electron microscopy.

Conclusion: The conserved luminal domain of lysosome-associated membrane proteins forms a previously unknown $\beta$-prism fold. Insights into the structure of the lysosomal glycoprotein coat were obtained by computational models of the LAMP-1 and LAMP-2 luminal regions.
\end{abstract}

\section{Background}

Lysosomes of mammalian cells typically appear as small, spherical bodies with amorphous, electron-dense cores and a single limiting membrane. The interior of lysosomes is acidic at $\mathrm{pH}$ 4.8. Lysosomes contain an array of hydrolases with acidic $\mathrm{pH}$ optimum that can degrade all cellular macromolecules. Three mechanisms provide substrates for lysosomal degradation: endocytosis, autophagy and phagocytosis.

Newly synthesized lysosomal proteins exit the transGolgi network in vesicles which fuse with endosomes [1]. Soluble lysosomal enzymes are tagged with mannose-6-

\footnotetext{
* Correspondence: konrad@buessow.com

+ Contributed equally

Department of Molecular Structural Biology, Helmholtz Centre for Infection Research, Inhoffenstr. 7, 38124 Braunschweig, Germany
}

phosphate and are sorted in the Golgi compartment by mannose-6-phosphate receptors. Lysosomal membrane proteins have sorting signals in their cytosolic domains. Early endosomes acquire lysosomal proteins and an acidic $\mathrm{pH}$ during their maturation to late endosomes [2]. Lysosomes can be distinguished from endosomes by the absence of mannose-6-phosphate receptors, a lower internal $\mathrm{pH}$ and a distinct morphology [3]. Lysosomes appear electron dense by comparison with endosomes and can be separated by density gradient centrifugation. Lysosomes may be regarded as storage organelles for degradative enzymes, with the degradation of substrates occurring mainly in hybrid organelles of late endosomes and (auto) phagosomes [4]. Endosomes deliver endocytosed molecules from the extracellular space for degradation, and also proteins provided by the ESCRT pathway. ESCRT
C Biomed Central 
complexes package ubiquitinated proteins into vesicles formed by inward budding of the endosomal limiting membrane. Fusion of a late endosome with lysosomes creates a hybrid organelle of intermediate density [5]. The hybrid organelle hydrolyses its cargo - macromolecules and intraluminal vesicles - and transports the small molecular products into the cytosol. The remaining lysosomal components are condensed and form new dense-core lysosomes [6].

The lysosome's degradative machinery is potentially harmful to its limiting membrane, since it is capable of degrading intact lipid membranes. The inside of the lysosomal membrane is protected from degradation, presumably by a high abundance of heavily glycosylated membrane proteins. The membrane is quickly degraded when its glycoconjugate-free outside is exposed to the lysosomal interior [7].

Lysosomes are characterized by a high abundance of heavily glycosylated membrane proteins. These proteins form a dense coat on the inside of the lysosomal membrane. The glycoprotein coat can be visualized by electron microscopy as a thin, electron translucent halo separating the membrane from the condensed core $[8,9]$. It can be stained by glycoprotein-specific reagents and its thickness ranges from 5 to $12 \mathrm{~nm}$ with an average of $8 \mathrm{~nm}[8,9]$. In comparison, the glycocalyx on the cell surface is much thicker, up to several micrometers [10]. Intracellular glycoprotein membrane coats were observed in lysosomes, endosomes, autophagosomes and secretory granules [9]. They are believed to protect vesicle membranes by limiting the access of degradative factors to the lipid bilayer.

The major lysosomal membrane proteins, the homologous LAMP-1 (lgp120, CD107a) and LAMP-2 (lgp110, CD107b), are the standard markers for the lysosomal compartment [11]. They are among the most extensively glycosylated proteins with glycan chains that outweigh the protein core and that include high-molecular-weight poly- $\mathrm{N}$-acetyllactosaminoglycans [12]. LAMP-1 and 2 are type-I membrane proteins of similar length and identical domain structure. The transmembrane region is followed by a short, $\mathrm{C}$-terminal cytosolic tail that comprises motifs for lysosomal targeting [1]. The luminal region comprises two similar N-glycosylated domains of about 160 residues, each with two conserved disulfide bonds (Figure 1). The two domains are separated by a proline-rich, O-glycosylated 'hinge' region of about 30 amino acid residues [13].

LAMP-1 and LAMP-2 are abundant proteins, representing 0.1 to $0.2 \%$ of total cell protein [14]. They are enriched in lysosomes, late endosomes and mature (auto) phagosomes. Both proteins are ubiquitous in human tissues and cell types [15]. Their expression is particularly pronounced in metabolically active cells. The LAMP-2 gene has three splice forms, LAMP-2A, $-2 \mathrm{~B},-2 \mathrm{C}$, which differ in the transmembrane and cytosolic regions [15]. The $L A M P-1$ gene encodes for a single transcript.

Considerable knowledge on LAMP function was derived from $L A M P-1$ and $L A M P-2$ gene knockout mice [16,17] and $L A M P-1 / 2$-negative cell lines [18]. Impaired fusion of phagosomes and autophagosomes with lysosomes was observed. LAMP-1 and 2 can complement each other to a large extent. Double $L A M P-1 / 2$ knockout leads to embryonic lethality. In contrast, $L A M P-1$ knockout mice are healthy [16]. They display upregulated levels of LAMP-2. Knockout of the LAMP-2 gene leads to elevated postnatal mortality [17]. Surviving mice have a phenotype that corresponds to Danon disease, a rare genetic condition caused by LAMP-2 deficiency [19]. Autophagosomes accumulate in several tissues of LAMP-2 negative mice. Danon disease entails muscle weakness, heart disease and mental retardation. It is associated with disturbed autophagosome maturation and extensive accumulation of autophagosomes in muscle cells.

LAMP proteins are important regulators of lysosome fusion with autophagosomes and phagosomes [20]. Macrophages lacking either LAMP-1 or LAMP-2 are capable of normal phagocytosis. However, knockout of both genes interferes with fusion of phagosomes with lysosomes [21,22]. Phagosomes lacking both LAMP-1 and 2 did not move from the periphery of the cell towards the perinuclear lysosomes [21]. In contrast to macrophages, LAMP-1 cannot compensate for lack of LAMP-2 in neutrophil phagocytes. LAMP-2 knockout mice suffer from a high prevalence of periodontitis because their neutrophils cannot keep the responsible bacteria in check [23].

LAMP-2 has been implicated in cholesterol transport from the lysosome $[18,24]$. It was shown that the membrane-proximal luminal domain of LAMP-2 is specifically required to rescue the cholesterol transport deficiency of $L A M P-1 / 2$ double knockout cells [24].

LAMP-1 and 2 are major components of the glycoconjugate coat on the inside of the lysosomal membrane. It was estimated that the concentration of LAMPs is sufficiently high for the formation of a nearly continuous layer on the inner surface of the lysosomal membrane [25]. It was, therefore, expected that their removal would destabilize lysosomes. However, depletion of LAMP-1 and 2 had no detectable effect on lysosome integrity. Removal of N-linked glycans with endoglycosidase $\mathrm{H}$ caused rapid degradation of LAMP-1 and LAMP-2, but did not destabilize lysosomes [26]. Lysosomes of LAMP$1 / 2$ knockout cells have abnormalities, but their limiting membranes are apparently intact [18]. Other glycoproteins and glycolipids might have provided sufficient membrane protection in these studies. Lysosomal hybrid organelles with larger limiting membrane surface and 


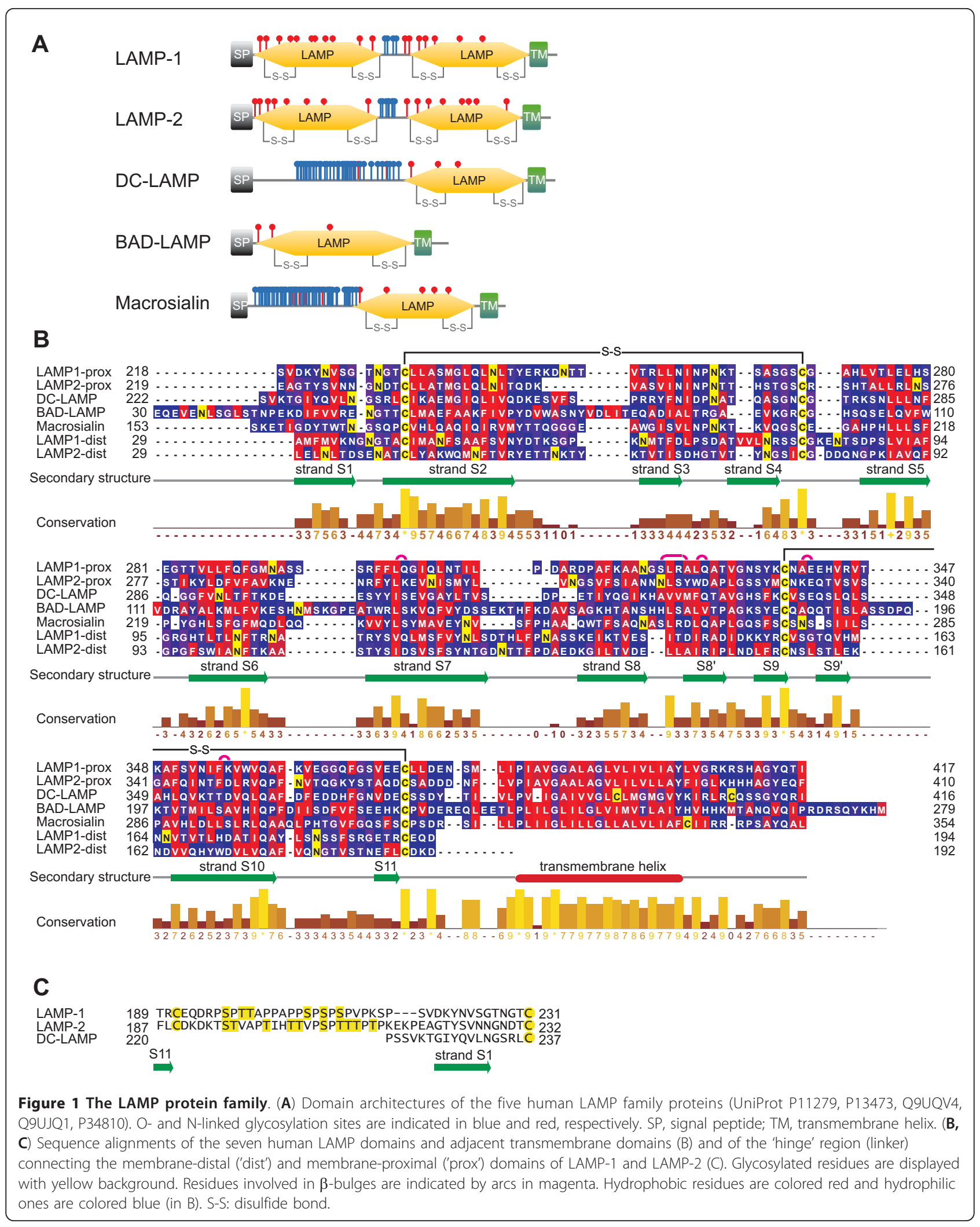


lower membrane glycoprotein density might be more dependent on LAMPs for protecting their membranes.

Intracellular glycoconjugate coats are found on the membranes of secretory granules [9]. During degranulation of Natural Killer (NK) or cytotoxic T-cells, cytotoxic effectors become activated, which can potentially harm the effector cells' cell membrane. LAMP-1 is a surface marker of NK cells that have degranulated. It can protect NK cells against their own cytotoxic effectors following degranulation (André Cohnen, University of Heidelberg, Carsten Watzl, Leibniz Research Centre for Working Environment, unpublished data).

Chaperone-mediated autophagy (CMA) is a lysosomal pathway for selective removal of damaged cytosolic proteins (reviewed in [27]). CMA effects direct transmembrane import of cytosolic proteins into the endolysosomal system. The LAMP-2 isoform LAMP-2A functions as a receptor for cytosolic proteins and also as essential component of the CMA translocation complex [28]. Cytosolic substrate proteins bind to monomers of LAMP-2A, which then multimerizes to form the complex required for substrate transmembrane import. Membrane-associated molecules of hsc70 actively disassemble LAMP-2A into monomers to initiate a new cycle of binding and translocation [28]. Expression of LAMP-2A normally declines in the liver of mice as they age. Genetic engineering for overexpression of LAMP-2A in the liver not only restored CMA, but also (macro)autophagy and proteasomal pathways to the levels observed in young animals. As a result, the age-related decline of liver function was significantly reduced [29].

The five human members of the LAMP protein family are characterized by a conserved 'LAMP domain' directly adjacent to the single transmembrane helix (Figure 1). LAMP- 1 and 2 are ubiquitous proteins, whereas DCLAMP (LAMP-3) [30], BAD-LAMP (UNC-46, C20orf103) [31] and macrosialin (CD68) [32] are only expressed in specific cell types.

Dendritic cells (DCs) are professional antigen-presenting cells with the task of activating immune responses. DCLAMP levels increase progressively during the differentiation of human DCs from hematopoietic bone marrow progenitor cells. DCs search for pathogens in tissues in contact with the external environment. They phagocytose pathogens, become activated and migrate to lymph nodes where they present pathogen-specific antigens on their cell surface using MHC class II molecules. DC-LAMP levels rises steeply upon activation of human DCs [30]. The protein co-localizes with MHC class II molecules in an intracellular compartment. DC-LAMP is a highly specific marker for mature DCs in humans and other mammals including cattle and pigs, but it is not expressed in DCs of mice [33].
Mammals, including mice, have a second cell type with high DC-LAMP expression: type II pneumocytes [34]. These cells secrete the lung's surfactant and, like DCs, can present antigens of pathogens on MHC class II molecules [35,36]. DC-LAMP co-localizes with MHC class II molecules on the limiting membrane of surfactant protein-containing organelles [34]. In chicken, DCLAMP expression is upregulated upon DC activation [37]. In contrast to mammals, DC-LAMP was found in nearly all chicken tissues tested.

The structural basis of the various and seemingly unrelated functions of the lysosome associated membrane proteins is currently unclear. No information about the three-dimensional structures of any of the highly glycosylated proteins that form the inner lysosomal membrane coat were available before this study and the structural basis for the electron microscopical appearance of the coat has remained unclear. Previously, we established a novel expression system for glycosylated proteins. With this system, stable cell lines for a number of LAMP domains were established and crystals of the membrane-proximal domain of human DCLAMP (LAMP-3) were obtained [38,39]. Here we report the structure solved with these crystals. Unexpected structural features and possible sites of molecular interactions were uncovered. In silico models of LAMP-1 and LAMP-2 were generated that allowed us to draw conclusions on the structure of the lysosomal membrane coat.

\section{Results}

\section{The DC-LAMP domain has a novel $\beta$-prism fold}

The crystal structure of the membrane-proximal domain of human DC-LAMP (Figure 1) was solved by multiwavelength anomalous dispersion (MAD) phasing and refined at a resolution of $2.8 \AA$ (Table 1 ). Two protein molecules denoted chain A and B are present in the asymmetric unit, which are related to each other by a two-fold non-crystallographic symmetry. Analysis with the protein interfaces, surfaces and assemblies service PISA [40] predicted that the domain is a monomer in solution, in correspondence with gel filtration results. Chains A and B have almost identical conformations except for one loop, which adopts two distinct conformations (discussed below). This is reflected by an r.m.s. distance for the aligned chains' $C_{\alpha}$ atoms of $0.39 \AA$ if this loop is excluded and of $2.1 \AA$ if the loop is included. If not otherwise noted, the following sections refer to chain A, which is based on a better defined electron density map.

The DC-LAMP domain consists of two $\beta$-sheets that form a "pseudo $\beta$-prism" (Figure 2). According to the SCOP database [41], the pseudo $\beta$-prism fold consists of 
Table 1 Data collection and refinement statistics.

\begin{tabular}{|c|c|c|c|}
\hline \multicolumn{4}{|l|}{ Data collection } \\
\hline Beamline & \multicolumn{3}{|c|}{ DESY X12 } \\
\hline Temperature $(K)$ & \multicolumn{3}{|c|}{100} \\
\hline Dataset type & Peak & Inflection point & High-energy remote \\
\hline Wavelength $(\AA)$ & 1.10371 & 1.10420 & 1.10009 \\
\hline Data range $\left(^{\circ}\right)$ & \multicolumn{3}{|c|}{180} \\
\hline Oscillation range $\left({ }^{\circ}\right)$ & \multicolumn{3}{|c|}{0.5} \\
\hline Space group & \multicolumn{3}{|c|}{$P 3_{1}$} \\
\hline Unit cell parameters ( $(̊)$ & \multicolumn{3}{|c|}{$a=b=53.0, c=143.5$} \\
\hline Resolution $(\AA)$ & \multicolumn{3}{|c|}{20 to 2.8 (2.95 to 2.8 ) } \\
\hline Unique reflections & $19,800(3,352)$ & $19,790(3,392)$ & $19,765(3,365)$ \\
\hline Redundancy & $2.84(2.84)$ & $2.83(2.82)$ & $2.84(2.84)$ \\
\hline Completeness (\%) & $90.0(94.5)$ & 89.9 (96.9) & $89.7(95.9)$ \\
\hline Mean $|/ \sigma|$ & $16.5(3.45)$ & $15.52(2.92)$ & $18.19(3.84)$ \\
\hline$R_{\text {merge }}{ }^{a}$ & $0.05(0.30)$ & $0.06(0.40)$ & $0.05(0.28)$ \\
\hline Mosaicity $\left(^{\circ}\right)$ & & 0.271 & \\
\hline Estimated Wilson $B\left(\AA^{2}\right)$ & & 54.1 & \\
\hline \multicolumn{4}{|l|}{ Refinement } \\
\hline$R_{\text {work }} \mathrm{b}$ & \multicolumn{3}{|c|}{0.2271} \\
\hline$R_{\text {free }}{ }^{c}$ & \multicolumn{3}{|c|}{0.2508} \\
\hline $\begin{array}{l}\text { Molecules in the asymmetric unit } \\
\text { (DC-LAMP/GICNAC/Ir) }\end{array}$ & \multicolumn{3}{|c|}{$2 / 2 / 4$} \\
\hline \multicolumn{4}{|l|}{ No. of atoms } \\
\hline Protein & \multicolumn{3}{|c|}{2,438} \\
\hline Hetero atoms & \multicolumn{3}{|c|}{32} \\
\hline Water & \multicolumn{3}{|c|}{10} \\
\hline Total & \multicolumn{3}{|c|}{2,480} \\
\hline Atomic displacement factor $B\left(\AA^{2}\right)$ & \multicolumn{3}{|c|}{61.3} \\
\hline Real space correlation coefficient ${ }^{d}$ & \multicolumn{3}{|c|}{0.882} \\
\hline \multicolumn{4}{|l|}{ r.m.s.d. from ideal } \\
\hline Bond lengths $(\AA)$ & \multicolumn{3}{|c|}{0.0056} \\
\hline Bond angles $\left({ }^{\circ}\right)$ & \multicolumn{3}{|c|}{1.023} \\
\hline \multicolumn{4}{|l|}{ Ramachandran plot } \\
\hline Favored (\%) & \multicolumn{3}{|c|}{90.9} \\
\hline Allowed (\%) & \multicolumn{3}{|c|}{6.8} \\
\hline Disallowed (\%) & \multicolumn{3}{|c|}{2.3} \\
\hline \multicolumn{4}{|c|}{$\begin{array}{l}\text { Values in parentheses account for the highest resolution shell. }{ }^{\mathrm{a}} R_{\text {merge }}=\sum_{h k l} \sum_{i}\left|I_{h k l, i}-\overline{I_{h k l}}\right| / \sum_{h k l} \sum_{i} I_{h k l, i}{ }^{\mathrm{b}} \\
R_{\text {work }}=\sum_{h k l}|| F_{\text {obs }}|-| F_{\text {calc }}|| / \sum_{h k l}\left|F_{\text {obs }}\right|\end{array}$} \\
\hline
\end{tabular}

a $\beta$-sandwich with one regular $\beta$-sheet and the other $\beta$-sheet bent in the middle with a set of aligned $\beta$ bulges. The triangular base of the domain's prism shape is $60 \AA$ wide and $35 \AA$ high and the prism's height is $35 \AA$. The domain's N- and C-termini are located on the 'front' $\beta$-sheet, which consists of $6 \beta$-strands (Figure 3 ). $\beta$-strands S1 and S3 are short and arranged in tandem, antiparallel to strand S2. Two more antiparallel $\beta$-strands, S10 and S9, are followed by the short C-terminal $\beta$-strand $\mathrm{S} 11$, which is arranged in parallel to S9. 


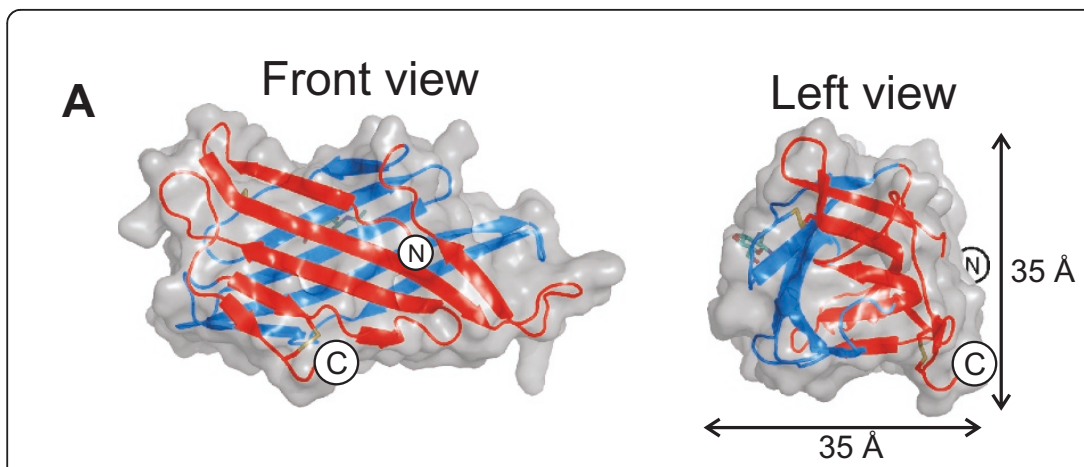

B
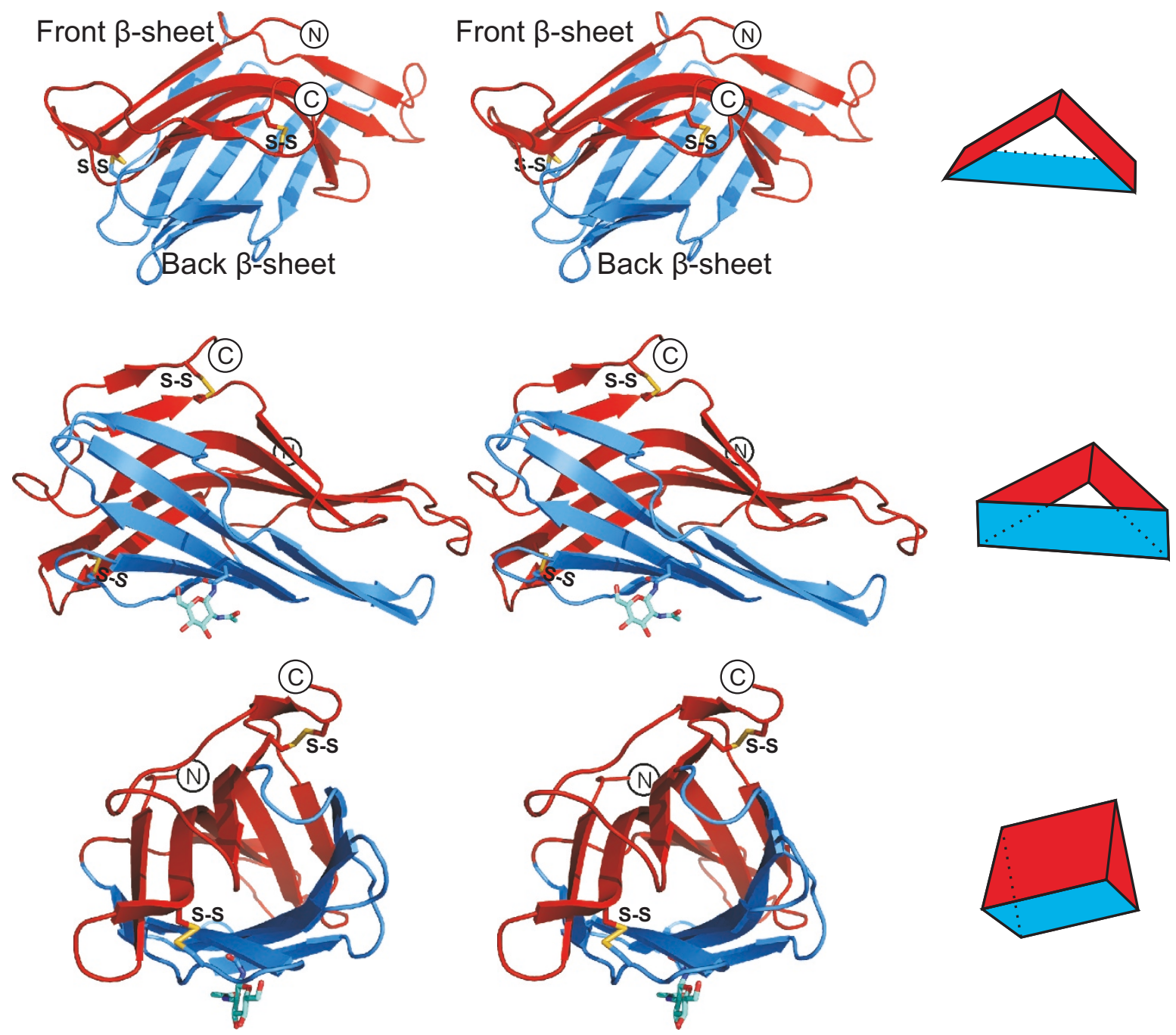

Figure 2 The structure of the DC-LAMP domain. (A) Different views of the domain's shape. The two $\beta$-sheets are drawn in red and blue. (B) Stereo views of the domain's $\beta$-prism shape. Schematic prism shapes are drawn on the right for orientation. The $\mathrm{N}$-acetyl-glucosamine residue is depicted as a stick drawing in cyan. 

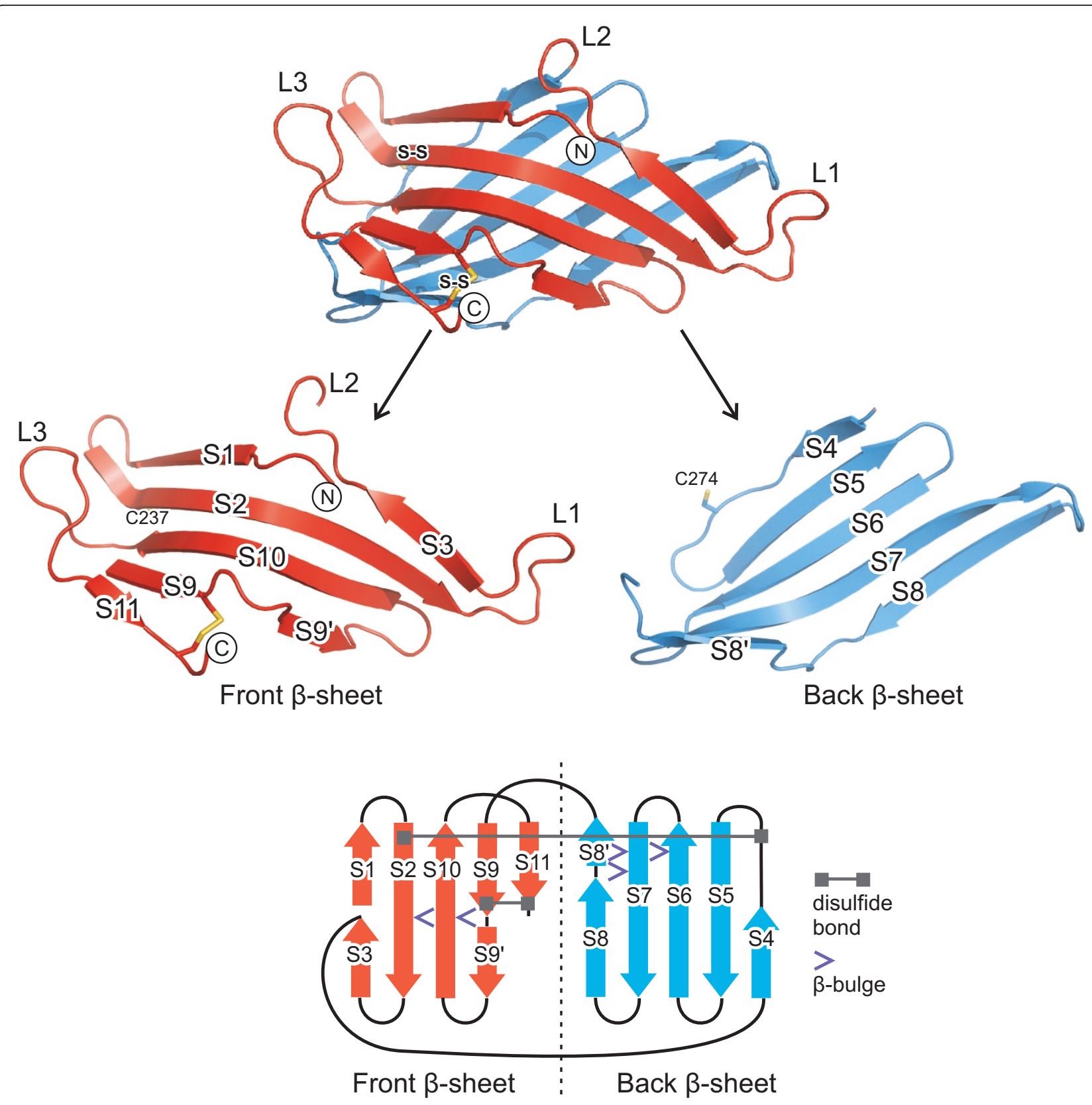

Figure 3 The $\beta$-strand arrangement of the DC-LAMP domain. The 'front' and 'back' $\beta$-sheets are drawn in red and blue, respectively. The cysteines that form the first disulfide bond (S-S) are labelled. $\beta$-strands and loops are identified as S1 to S11 and L1 to L3, respectively. The topology of the $\beta$-sheets is drawn schematically in the lower part with sheets opened out.

The front $\beta$-sheet is bent in the middle by two connected $\beta$-bulges [42], which are formed by the $\beta$-strand pairs S2/S10 and S10/S9 (Figure 4). This bending forms the domain's triangular prism shape and it opens a hydrophobic pocket between the sheets, constituting a possible binding site for small molecules (Figure 5A).

The 'back' $\beta$-sheet consists of five antiparallel $\beta$-strands (Figure 3). Strand S4 comprises only four residues, 268 to 271 , but the polypeptide chain continues in a $\beta$-strand- like conformation up to residue 275 . It is distorted by the disulfide bond formed by cysteines 274 and 311 . The back $\beta$-sheet is flat, except for the lower left corner, which is bent as if to close the opening of the domain created by the bending of the front $\beta$-sheet (Figure 2B). The bending of the back $\beta$-sheet is caused by three $\beta$-bulges between strands S6, S7 and S8 (Figure 4).

The domain's $\beta$-strands are connected by $\beta$-turns and three loops. Loop L2 links the front $\beta$-sheet with the 

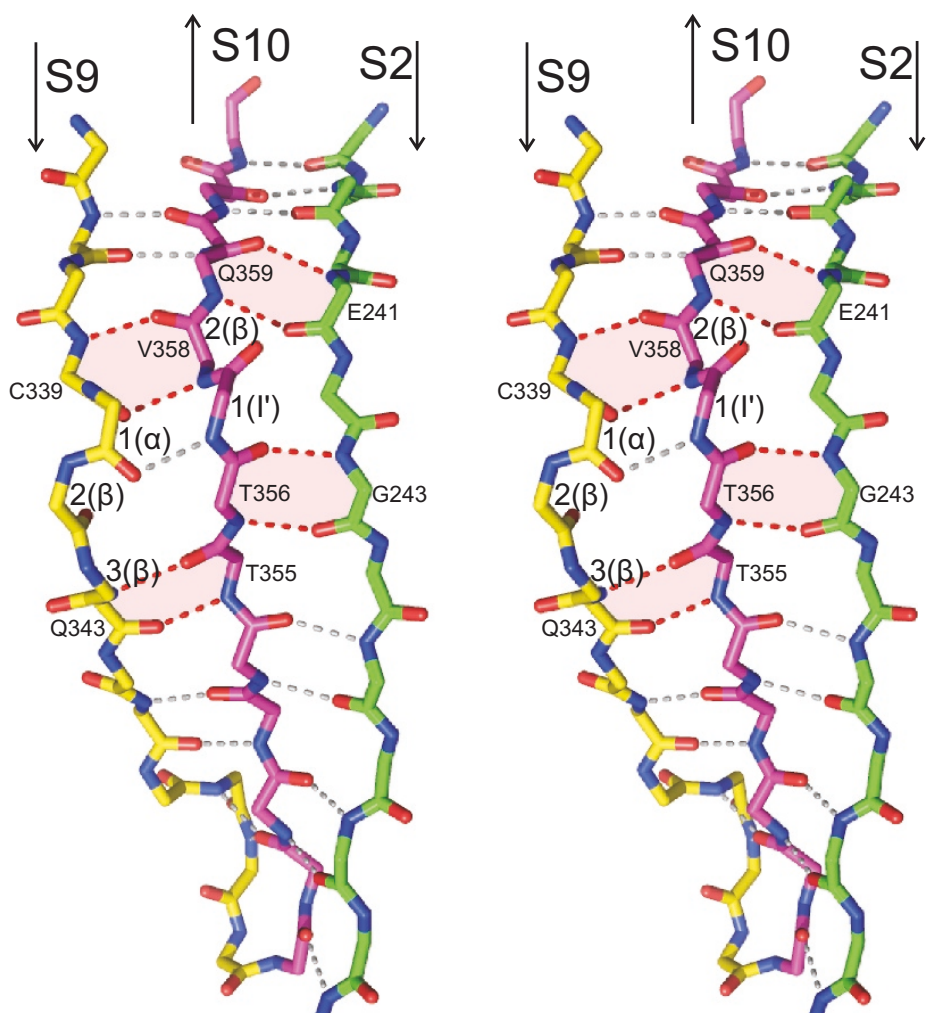

Front

$\beta$-sheet
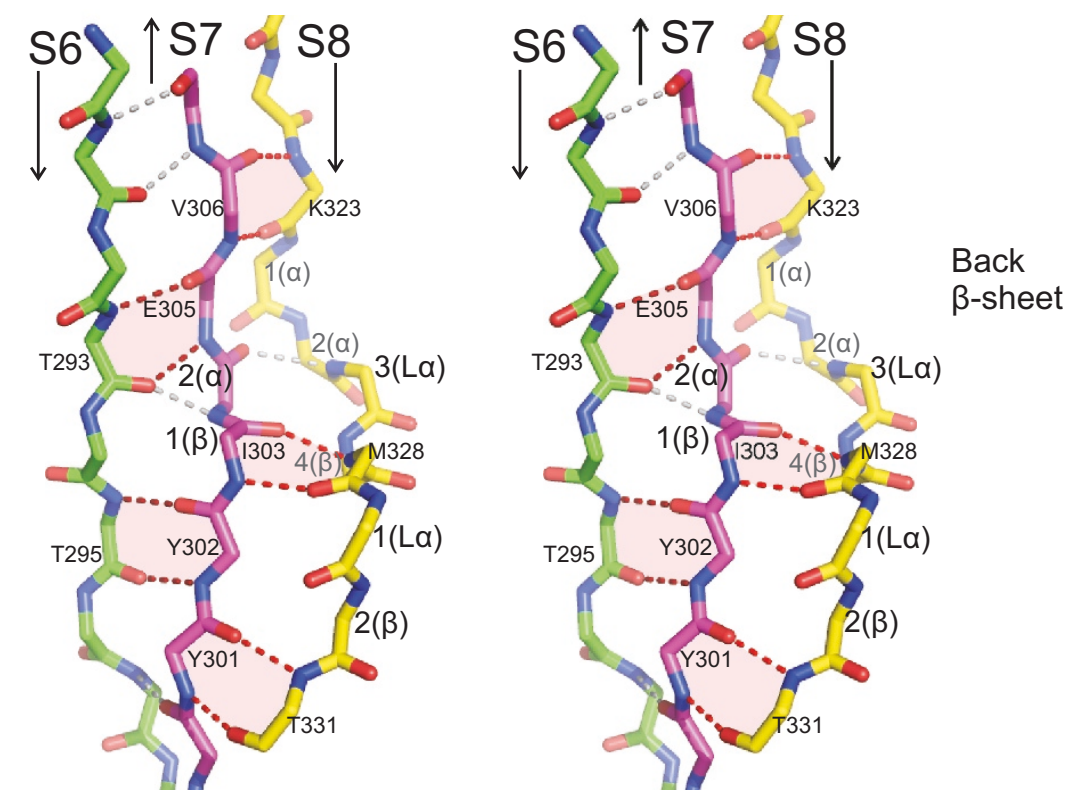

Figure 4 Stereo views of the $\beta$-bulges. The $\beta$-bulges that bend the front and back $\beta$-sheets are shown. Main chain atoms of parts of $\beta$-strands are shown as stick drawings. Bulged residues are numbered and their conformations are given in parentheses $(\alpha, \alpha$-helix; $\beta, \beta$-strand; l', type l' $\beta$ turn; $L \alpha$, left-handed $\alpha$-helix). Hydrogen bond pairs that flank $\beta$-bulges are shown in red and the corresponding residues are labelled. Other inter-main chain hydrogen bonds are drawn in grey. 


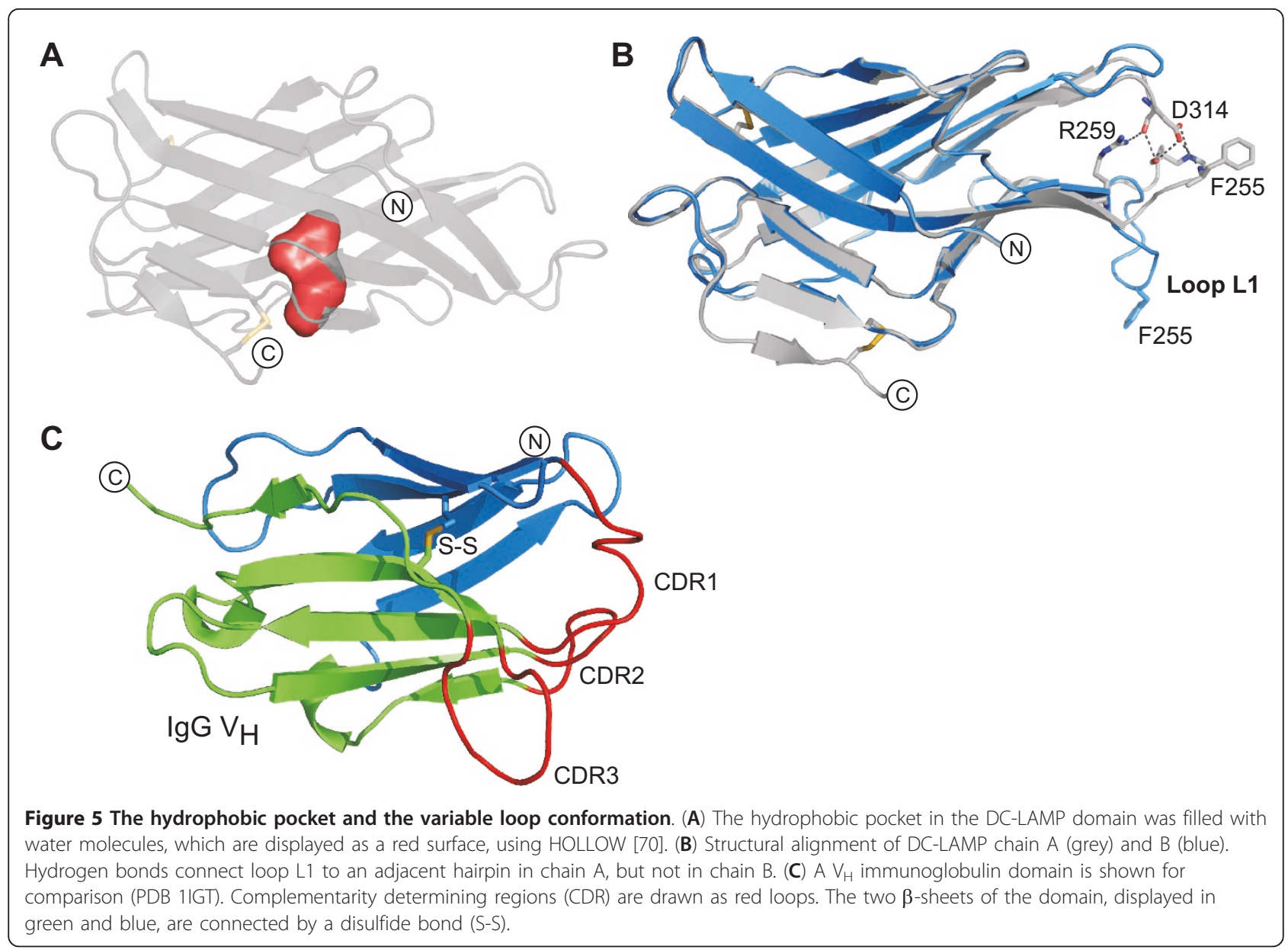

back $\beta$-sheet (Figure 3). Two more loops of 6 and 10 residues connect strands S2 and S3 (Loop L1) and S10 and S11 (Loop L3), respectively. The conformation of loop L1 and the adjacent $\beta$-hairpin formed by strands S7 and S8 differs between chains A and B, due to crystal contacts, indicating that these regions are flexible in solution (Figure 5B). Several hydrogen bonds link loop L1 and the hairpin in chain A, but not in chain B.

According to the SCOP database [41], only two proteins are known to contain pseudo $\beta$-prism domains, a carbohydrate receptor binding protein of Lactococcus lactis phage P2 (UniProt Q71AW2, PDB 1ZRU, 2-140) [43] and a tail protein of Bordetella phage BPP-1 (UniProt Q775D6, PDB 1YU0, 5-170) [44]. The topology of the $\beta$-sheets (that is, the order of the $\beta$-strands) of the DC-LAMP domain differs from the other pseudo $\beta$ prism structures. The DC-LAMP domain therefore represents a novel fold (Alexey Murzin, personal communication).

Two disulfide bonds and an $\mathrm{N}$-acetylglucosamine residue connected to Asn291 were visible in the DC-LAMP domain's electron density map (Figure 2B). The first disulfide bond stabilizes the $\beta$-prism by linking its two sheets. The second disulfide bond, linking the front $\beta$ sheet and the domain's $C$-terminus, strengthens the connection of the $\mathrm{C}$-terminal transmembrane helix to the center of the front $\beta$-sheet. Interestingly, the $\mathrm{N}$-acetylglucosamine at Asn291 participated in formation of the crystal lattice by forming a hydrogen bond to Gly287 of a neighboring protein molecule.

The LAMP domain shares features with immunoglobulin (Ig) domains (Figure 5C). Both domain types have an all- $\beta$ fold of comparable size stabilized by a conserved disulfide bond between their two $\beta$-sheets. The variable Ig domains of antibodies contain three flexible loops forming the antigen-binding site, the complementarity determining regions (CDRs). Loop L1 and the adjacent $\beta$-hairpin of the LAMP domain are also flexible (Figure 5B) and might provide a site for specific molecular interactions.

\section{Models of glycosylated LAMP domains}

The N-terminal segment of the luminal region of DCLAMP is proline-rich and densely $\mathrm{O}$-glycosylated 
(residues 28 to 221, Figure 1A), which implies an elongated, stiffened conformation due to steric restraints imposed by the glycan moieties [45]. A model of glycosylated full length DC-LAMP was drawn to scale with the domain's C-terminus pointing down towards the membrane (Figure 6). In this orientation, the protein's $\mathrm{N}$-terminal segment is linked to the domain's side at about half height, suggesting an orientation of the Nterminal segment along the membrane.

The highly abundant LAMP proteins 1 and 2 are the main components of the thin coat present on the inside of lysosomal membranes. The conformation of their luminal domains in the coat is currently unclear. Structural models of the membrane-distal and membraneproximal domains of LAMP-1 and LAMP-2 were generated by comparative modelling with [46] using DCLAMP chain A as the template. Glycans of complex type were attached to the models with [47] and GLYCAM [48]. The resulting glycosylated domain structures had diameters of 6 to $9 \mathrm{~nm}$. This corresponds to the thickness of the glycoconjugate coat of the lysosomal membrane, which was reported to range from 5 to $12 \mathrm{~nm}$ [8] (Figure 6).

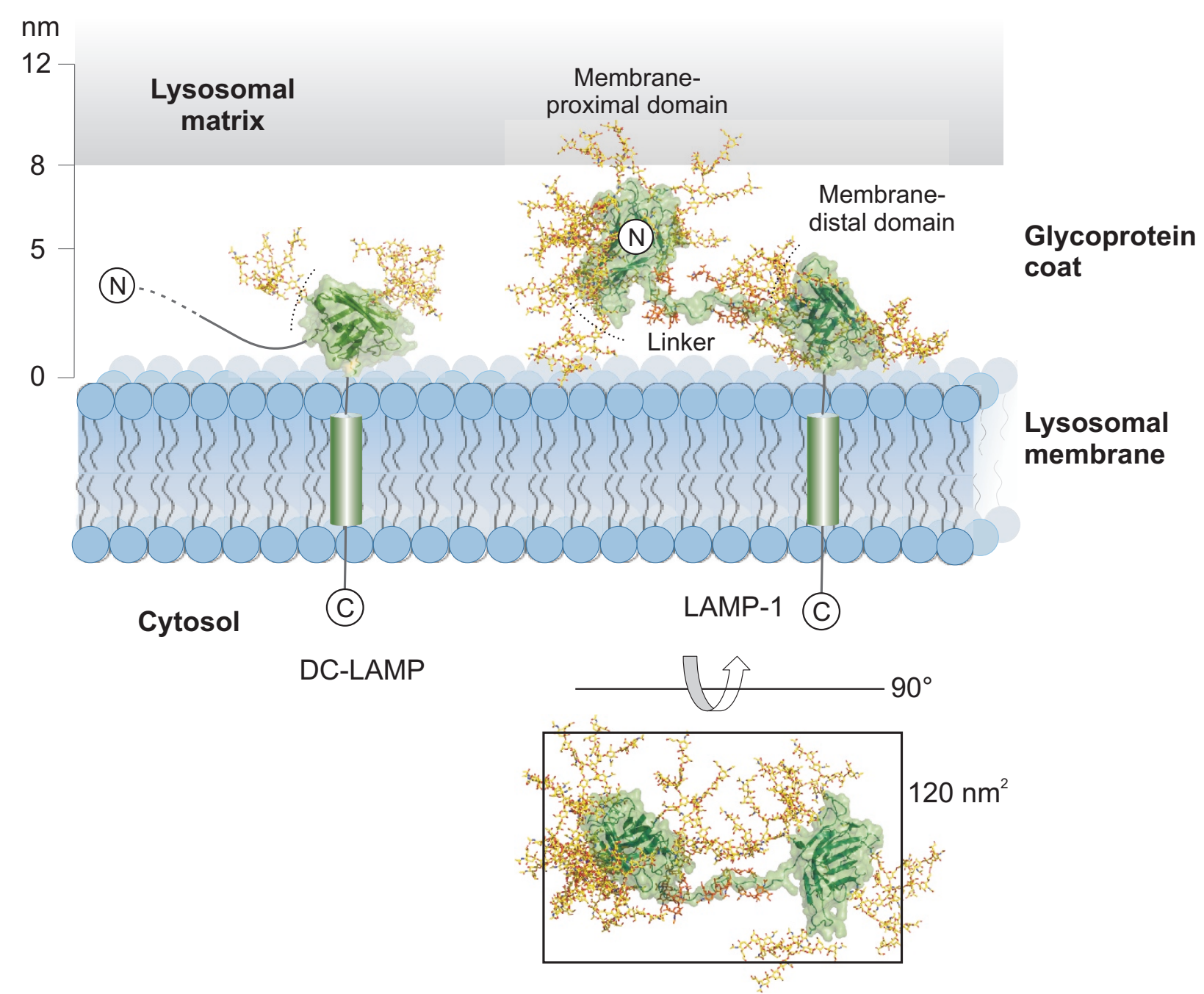

Figure 6 Model of lysosomal membrane proteins and the glycoprotein coat. Structural models of glycosylated DC-LAMP and LAMP-1 were drawn to scale. The models are based on the DC-LAMP crystal structure and a hypothetical in silico model of LAMP-1. The thickness of the glycoprotein coat was reported to range from 5 to $12 \mathrm{~nm}$ with an average of $8 \mathrm{~nm}$. The membrane-distal, N-terminal domain of LAMP-1 may adopt other positions. Dotted lines indicate putative binding sites consisting of the flexible loop L1 and an adjacent $\beta$-hairpin (Figure 5B). A box corresponding to $120 \mathrm{~nm}^{2}$ surface area was drawn around a top view of LAMP-1. Polypeptides are depicted in green and glycans in yellow. 
The two domains of LAMP-1 are connected by a linker of 23 residues, which comprises 11 prolines and 6 O-glycosylation sites in LAMP-1 (Figure 1C). This implies an elongated conformation lacking secondary structure and limited flexibility of the peptide backbone. The linker of LAMP-2 has similar length but more glycosylation sites. Conformational properties of the LAMP-1 linker were analysed by computational folding simulation. The sequence ${ }^{196}$ PSPTTAPPAPPSPSPSP ${ }^{212}$ was subjected to a $12 \mathrm{~ns}$ simulation with AMBER force fields. The initial structure had an elongated $\beta$-strand conformation and carried sialylated O-glycans on the six Ser/Thr residues. During the simulation, folding was not observed (Figure 7). Residues departed from the initial $\beta$ strand conformation only transiently, except for prolines 203 and 206, which adopted $\alpha$-helical conformations permanently. High values for the radius of gyration indicated elongated conformations throughout the simulation (Figure 7B). During the simulation, root-mean-square deviations of the backbone atoms from the lowest energy structure were in the order of 3 to $5 \AA$, indicated a high degree of structural flexibility (Figure 7B).

According to the in silico models, the N-termini of the membrane-proximal domains of LAMP-1 and LAMP-2 are localized on the side, as described above for the DCLAMP domain, allowing their $\mathrm{N}$-terminal, membrane-
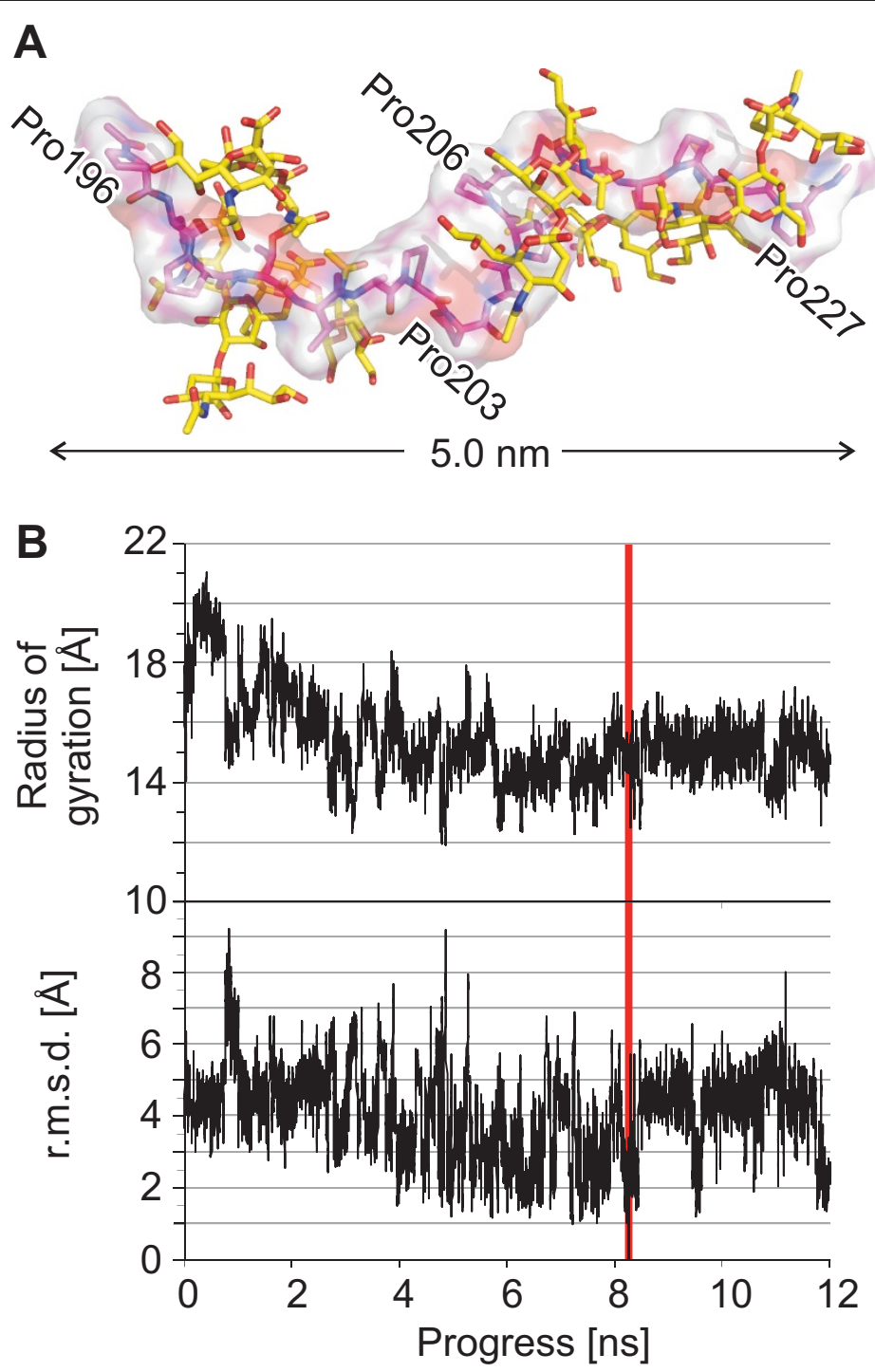

Figure 7 Molecular modeling. (A) The structure of the lowest energy obtained by molecular dynamics simulation is shown as a stick model and a van der Waals surface with pink carbon atoms. Glycans are shown with yellow carbon atoms. Prolines 203 and 206 have $\alpha$-helical conformations. (B) Radius of gyration values during the simulation and r.m.s. deviations of the backbone atoms from the structure of lowest energy (marked in red). The peptide's lowest-energy structure had a radius of gyration of $14.6 \AA$, compared to $17.9 \AA$ for the initial structure. 
distal domains to localize close to the membrane. The models of the LAMP-1 domains and linker were combined into a model of the complete molecule (Figure 6). In the model, the dimensions of the luminal domain of LAMP-1 agree well with the reported thickness of the lysosomal glycoprotein coat. The model represents a possible conformation in which the linker is oriented horizontally and the N-terminal domain is located relatively close to the membrane. Alternative conformations with the linker pointing upwards appear less favorable due to steric hindrance and electrostatic repulsion of the sialic acid groups on the $\mathrm{N}$ - and O-linked glycans.

\section{Discussion}

The crystal structure of the membrane-proximal domain of DC-LAMP reveals a novel $\beta$-prism fold. It is the first structure reported for the heavily glycosylated lysosomal membrane proteins. The structure proves that the proteinaceous core of these proteins can adopt a globular compact fold that is not fundamentally different from proteins with less glycosylation.

The structure explains the complete conservation of the pair of disulfide bonds in the LAMP protein family. The first disulfide bond stabilizes the $\beta$-prism, while the second disulfide bond fixes the domain's $\mathrm{C}$-terminus to the center of the kinked $\beta$-sheet. The center of the sheet is thereby linked to the transmembrane helix. Loop L3, the flexible loop L1 and the adjacent $\beta$-hairpin point sideways. In this arrangement, the loops would be in a suitable position for interacting with luminal domains of neighboring membrane proteins.

The LAMP family is characterized by a conserved, membrane-proximal domain. Sequence conservation is not restricted to this domain, but includes the adjacent transmembrane helices (Figure 1B). All human LAMPs contain a conserved proline and two conserved glycine residues in the transmembrane helix. Glycine residues mediate interactions of transmembrane helices in membrane proteins [49]. In the course of chaperone-mediated autophagy (CMA), LAMP-2A oligomerizes into multimeric complexes. Mutation of the conserved glycines in the LAMP-2A transmembrane region to alanines inhibits oligomerization and significantly reduces CMA activity [28]. The lysosomal polypeptide transporter TAPL (ABCB9) has recently been identified as a specific binding partner of LAMP-1 and LAMP-2 [50]. The interaction appears to be mediated by transmembrane regions: the binding site for the LAMPs is localized in the N-terminal domain of TAPL, which comprises four transmembrane helices but no globular domains. The LAMP-2B isoform is recognized exclusively by TAPL, which differs from LAMP-2A only in the transmembrane region and the cytosolic tail. The structure solved in this study identified a possible protein binding site (Figure $5 \mathrm{~B}$ ). It is possible that LAMPs self-oligomerize or recognize other lysosomal membrane proteins by simultaneous interactions with their luminal and transmembrane regions. The LAMP family member unc-46 (BAD-LAMP) and the vesicular GABA transporter depend on each other for their vesicular sorting [51]. This phenomenon might be due to molecular interaction of the two proteins.

The dimensions of the in silico models are consistent with literature data on the thickness of the glycoprotein coat on the lysosomal membrane (Figure 6) and the density of LAMP molecules on the lysosomal membrane. In BHK cells, the surface area of lysosomal and LAMP-1 positive prelysosomal membranes was determined as $370 \mu \mathrm{m}^{2} /$ cell [52]. The average volume of the cells was $1,400 \mu \mathrm{m}^{3}$ [53]. LAMP-1 represents approximately $0.1 \%$ of the total cellular protein content of 200 to $250 \mathrm{mg} / \mathrm{ml}$ [25]. This amounts to a density of LAMP-1 in lysosomal membranes of approximately 2,600 molecules $/ \mu \mathrm{m}^{2}$. The footprint of the LAMP-1 model in Figure 6 is about $120 \mathrm{~nm}^{2}$, which would implicate that about one third of lysosomal membranes is covered by LAMP-1. The model thus supports the concept of a continuous glycoprotein layer formed by LAMP-1, the similar LAMP-2 and other lysosomal proteins.

The luminal regions of lysosomal membrane proteins are typically small and do not contain more than a single folded domain. A comprehensive list of 45 lysosomal membrane proteins [54] was analysed with PFAM. Multidomain proteins were not found in this list and immunoglobulin or fibronectin domains, which are frequent in extracellular multidomain regions, were not present. This result corresponds to the thickness of the lysosomal glycoprotein coat of $8 \mathrm{~nm}$ on average, which is low in comparison to the glycocalyces on cell membranes of several hundred nanometers thickness [55].

It is generally believed that intracellular glycoprotein coats protect the limiting membranes of degradative vesicles against acid hydrolases. LAMP-1 protects natural killer cells against their own cytotoxic effectors. Besides protection, glycoconjugate coats on membranes of lysosomes and granules might be important in preventing attachment of the condensed content with the membrane, thereby supporting release of the content during phago-lysosomal fusion or exocytosis, respectively.

\section{Conclusion}

This paper shows that the conserved domain of lysosomeassociated membrane proteins forms a previously unknown $\beta$-prism fold with several unique structural features. The low thickness of the lysosomal inner membrane coat correlates with the compactness and membraneproximity of the luminal regions of the heavily glycosylated lysosomal membrane proteins. Knowledge of the 
LAMPs' globular domains and their sites of possible molecular interaction will support continued research on the role of these proteins in the cell.

\section{Methods}

Multiple alignment, modelling

Multiple alignments were made with Jalview [56] and the L-INS-i method of MAFFT [57]. Comparative modelling of LAMP domains was performed with MODELLER (University of California, San Francisco, CA, USA) [46]. Complex type $\mathrm{N}$-linked glycans were attached to structural models with the GLYPROT server [47]. The attached glycan was a 17 -mer with 4 sialylated $\mathrm{N}$-acetyllactosamine antenna (LinucsID 26155 in the Glycosciences glycan database [47]).

A structural representation of the linker ${ }^{196}$ PSPTTAPPAPPSPSPSP ${ }^{212}$ between the domains of human LAMP-1 was created in an elongated conformation $(\Phi, \Psi$ approximately $-82^{\circ}, 125^{\circ}$ ) with PyMOL (Schrödinger LLC, New York, NY, USA) and Swiss-PdbViewer [58]. The sialylated trisaccharide $\alpha$ Neu5Ac(2-3) $\beta$ Gal(1-3) $\alpha$ GalNAc was attached to the 6 reported O-glycosylation sites [59] using GLYCAM [48]. Molecular dynamics simulations were performed with AMBER11 [60] and the GLYCAM06 force field [61] in an implicit generalized Born solvent. The initial structure was minimized by 500 steps of steepest descent followed by 500 of conjugate gradient. Then, the system was heated, with a time step of $0.5 \mathrm{fs}$, for $1 \mathrm{ps}$ at $10 \mathrm{~K}$, followed by a gradient of $4 \mathrm{ps}$ to $300 \mathrm{~K}$ and an equilibration step of $500 \mathrm{ps}$ at $300 \mathrm{~K}$. The heated system was subjected to $12 \mathrm{~ns}$ simulation at $300 \mathrm{~K}$ with a time step of $2 \mathrm{fs}$ and a heat bath coupling time constant of $0.5 \mathrm{ps}$.

\section{Protein production, crystallization, and heavy metal derivatization}

The membrane-proximal domain of human DC-LAMP (UniProt Q9UQV4, 222-381) with a C-terminal $\mathrm{His}_{6}$-tag was produced with a stable $\mathrm{CHO}$ cell line, purified by nickel chromatography and gelfiltration, deglycosylated and crystallized as described $[38,39]$. Crystals were soaked for 0.5 to 10 minutes in $14 \mathrm{mM}$ Ammonium hexachloriridate(III)hydrate (Hampton Research, Aliso Viejo, CA, USA) in mother liquor and immediately shock cooled in liquid nitrogen.

\section{Data collection and structure determination}

Three sets of X-ray diffraction data were collected at beamline X12 of the EMBL outstation (Hamburg, Germany) at wavelengths of 1.10371, 1.10420 and 1.10009 $\AA$ which correspond to the peak, inflection point and high-energy remote of the Ir absorption spectrum, respectively. Data were processed with XDS [62] in space group $\mathrm{P} 3_{1}$ to a high-resolution limit of $2.8 \AA$. The calculation of the Matthews coefficient [63] and a
MOLREP self-rotation function [64] revealed the presence of two DC-LAMP molecules in the asymmetric unit. The phase problem was solved by multi-wavelength anomalous dispersion with Phenix.autosol of the Phenix software suite [65]. Phenix.autobuild was used to build an initial model of DC-LAMP but succeeded only in building parts of one of the two molecules in the asymmetric unit. This partial model was used as a search model for molecular replacement with Phaser [66], which resulted in the positions of both DC-LAMP molecules. The structure was completed by iterative steps of manual rebuilding in Coot [67] and refinement with Phenix.refine [65]. The complete data collection and refinement statistics are shown in Table 1. Superpositions were carried out and r.m.s. deviations were calculated with the UCSF Chimera package (University of California, San Francisco, CA, USA) [68]. The secondary structure was analyzed using the DSSP algorithm [69] and figures were prepared with PyMOL.

\section{PDB Accession Code}

Coordinates and experimental structure factors have been deposited in the Protein Data Bank with accession code [PDB:4AKM].

\section{Abbreviations}

BHK: baby hamster kidney; CDR: complementarity determining region; $\mathrm{CHO}$ : Chinese hamster ovary; CMA: chaperone-mediated autophagy; DC: dendritic cell; dist: membrane-distal; ESCRT: endosomal sorting complex required for transport; Gal: galactose; GalNAc: N-acetylgalactosamine; GlcNAc: Nacetylglucosamine; Ig: immunoglobulin; LAMP: lysosome-associated membrane protein; Igp: Iysosomal membrane glycoprotein; Neu5Ac: Nacetylneuraminic acid; NK: natural killer; prox: membrane-proximal; r.m.s.(d.): root-mean-square (difference); RSCC: real space correlation coefficient; TAPL: transporter associated with antigen processing-like.

\section{Acknowledgements}

We are grateful to Dr. Björn Klink for supporting crystallization, Christian Kambach for critical reading and Joachim Reichelt for help with molecular modelling. We thank Vitali Maffenbeier for experimental support and Paul Saftig for valuable discussions. Protein production was supported by the Helmholtz Protein Sample Production Facility (PSPF).

\section{Authors' contributions}

SW prepared the derivatized crystals. JK and SW collected X-ray diffraction data sets. JK solved and refined the crystal structure. KB conceived of and coordinated the study, carried out the modeling and drafted the manuscript. All authors contributed to the final manuscript.

Competing interests

The authors declare that they have no competing interests.

Received: 24 April 2012 Accepted: 19 July 2012 Published: 19 July 2012

\section{References}

1. Braulke T, Bonifacino JS: Sorting of lysosomal proteins. Biochim Biophys Acta 2009, 1793:605-614.

2. Huotari J, Helenius A: Endosome maturation. Embo J 2011, 30:3481-3500.

3. Pillay CS, Elliott E, Dennison C: Endolysosomal proteolysis and its regulation. Biochem J 2002, 363:417-429.

4. Luzio JP, Pryor PR, Bright NA: Lysosomes: fusion and function. Nat Rev Mol Cell Biol 2007, 8:622-632. 
5. Bright NA, Gratian MJ, Luzio JP: Endocytic delivery to lysosomes mediated by concurrent fusion and kissing events in living cells. Curr Biol 2005, 15:360-365.

6. Pryor PR, Mullock BM, Bright NA, Gray SR, Luzio JP: The role of intraorganellar $\mathrm{Ca}^{2+}$ in late endosome-lysosome heterotypic fusion and in the reformation of lysosomes from hybrid organelles. J Cell Biol 2000, 149:1053-1062

7. Henell F, Ericsson JL, Glaumann H: Degradation of phagocytosed lysosomes by Kupffer cell lysosomes. Lab Invest 1983, 48:556-564

8. Neiss WF: A coat of glycoconjugates on the inner surface of the lysosomal membrane in the rat kidney. Histochemistry 1984, 80:603-608.

9. Neiss WF: Ultrachemistry of Intracellular Membrane Glycoconjugates Berlin, Heidelberg: Springer-Verlag; 1986

10. Ebong EE, Macaluso FP, Spray DC, Tarbell JM: Imaging the endothelial glycocalyx in vitro by rapid freezing/freeze substitution transmission electron microscopy. Arterioscler Thromb Vasc Biol 2011, 31:1908-1915.

11. Saftig P: Lysosomal membrane proteins. In Lysosomes. Edited by: Saftig P. New York: Springer: 2005:37-49

12. Carlsson SR, Fukuda M: The polylactosaminoglycans of human lysosomal membrane glycoproteins lamp-1 and lamp-2. Localization on the peptide backbones. J Biol Chem 1990, 265:20488-20495.

13. Carlsson SR, Fukuda M: Structure of human lysosomal membrane glycoprotein 1. Assignment of disulfide bonds and visualization of its domain arrangement. J Biol Chem 1989, 264:20526-20531.

14. Chen JW, Pan W, D'Souza MP, August JT: Lysosome-associated membrane proteins: Characterization of LAMP-1 of macrophage P388 and mouse embryo 3T3 cultured cells. Arch Biochem Biophys 1985, 239:574-586.

15. Furuta K, Yang X-L, Chen J-S, Hamilton SR, August JT: Differential expression of the lysosome-associated membrane proteins in normal human tissues. Arch Biochem Biophys 1999, 365:75-82.

16. Andrejewski N, Punnonen EL, Guhde G, Tanaka Y, Lullmann-Rauch $R$ Hartmann D, von Figura K, Saftig P: Normal lysosomal morphology and function in LAMP-1-deficient mice. J Biol Chem 1999, 274:12692-12701.

17. Tanaka Y, Guhde G, Suter A, Eskelinen EL, Hartmann D, Lullmann-Rauch R, Janssen PM, Blanz J, von Figura K, Saftig P: Accumulation of autophagic vacuoles and cardiomyopathy in LAMP-2-deficient mice. Nature 2000, 406:902-906.

18. Eskelinen EL, Schmidt CK, Neu S, Willenborg M, Fuertes G, Salvador N, Tanaka Y, Lullmann-Rauch R, Hartmann D, Heeren J, von Figura K, Knecht E, Saftig P. Disturbed cholesterol traffic but normal proteolytic function in LAMP-1/ LAMP-2 double-deficient fibroblasts. Mol Biol Cell 2004, 15:3132-3145.

19. Nishino I, Fu J, Tanji K, Yamada T, Shimojo S, Koori T, Mora M, Riggs JE, Oh SJ, Koga Y, Sue CM, Yamamoto A, Murakami N, Shanske S, Byrne E, Bonilla E, Nonaka I, DiMauro S, Hirano M: Primary LAMP-2 deficiency causes X-linked vacuolar cardiomyopathy and myopathy (Danon disease). Nature 2000, 406:906-910.

20. Saftig P, Beertsen W, Eskelinen EL: LAMP-2: a control step for phagosome and autophagosome maturation. Autophagy 2008, 4:510-512.

21. Huynh KK, Eskelinen EL, Scott CC, Malevanets A, Saftig P, Grinstein S: LAMP proteins are required for fusion of lysosomes with phagosomes. Embo $J$ 2007, 26:313-324

22. Binker MG, Cosen-Binker LI, Terebiznik MR, Mallo GV, McCaw SE, Eskelinen EL, Willenborg M, Brumell JH, Saftig P, Grinstein S, Gray-Owen SD: Arrested maturation of Neisseria-containing phagosomes in the absence of the lysosome-associated membrane proteins, LAMP-1 and LAMP-2. Cell Microbiol 2007, 9:2153-2166.

23. Beertsen W, Willenborg M, Everts V, Zirogianni A, Podschun R, Schroder B, Eskelinen EL, Saftig P: Impaired phagosomal maturation in neutrophils leads to periodontitis in lysosomal-associated membrane protein-2 knockout mice. J Immunol 2008, 180:475-482.

24. Schneede A, Schmidt CK, Holtta-Vuori M, Heeren J, Willenborg M, Blanz J, Domanskyy M, Breiden B, Brodesser S, Landgrebe J, Sandhoff K, Ikonen E, Saftig P, Eskelinen EL: Role for LAMP-2 in endosomal cholesterol transport. J Cell Mol Med 2011, 15:280-295.

25. Granger BL, Green SA, Gabel CA, Howe CL, Mellman I, Helenius A: Characterization and cloning of Igp110, a lysosomal membrane glycoprotein from mouse and rat cells. J Biol Chem 1990, 265:12036-12043.

26. Kundra R, Kornfeld S: Asparagine-linked oligosaccharides protect Lamp-1 and Lamp-2 from intracellular proteolysis. J Biol Chem 1999, 274:31039-31046.
27. Kon M, Cuervo AM: Chaperone-mediated autophagy in health and disease. Febs lett 2010, 584:1399-1404.

28. Bandyopadhyay U, Kaushik S, Varticovski L, Cuervo AM: The chaperonemediated autophagy receptor organizes in dynamic protein complexes at the lysosomal membrane. Mol Cell Biol 2008, 28:5747-5763.

29. Zhang C, Cuervo AM: Restoration of chaperone-mediated autophagy in aging liver improves cellular maintenance and hepatic function. Nat Med 2008, 14:959-965

30. de Saint-Vis B, Vincent J, Vandenabeele S, Vanbervliet B, Pin JJ, Ait-Yahia S, Patel S, Mattei MG, Banchereau J, Zurawski S, Davoust J, Caux C, Lebecque S: A novel lysosome-associated membrane glycoprotein, DCLAMP, induced upon DC maturation, is transiently expressed in MHC class II compartment. Immunity 1998, 9:325-336.

31. Defays A, David A, de Gassart A, De Angelis Rigotti F, Wenger T, Camossetto V, Brousset P, Petrella T, Dalod M, Gatti E, Pierre P: BAD-LAMP is a novel biomarker of nonactivated human plasmacytoid dendritic cells. Blood 2011, 118:609-617.

32. Rabinowitz SS, Gordon S: Macrosialin, a macrophage-restricted membrane sialoprotein differentially glycosylated in response to inflammatory stimuli. J Exp Med 1991, 174:827-836.

33. Salaun B, de Saint-Vis B, Clair-Moninot V, Pin J-J, Barthélemy-Dubois C, Kissenpfennig A, Peronne C, Bates E, Mattei M-G, Lebecque S: Cloning and characterization of the mouse homologue of the human dendritic cell maturation marker CD208/DC-LAMP. Eur JImmunol 2003, 33:2619-2629.

34. Salaun B, de Saint-Vis B, Pacheco N, Pacheco Y, Riesler A, Isaac S, Leroux C, Clair-Moninot V, Pin JJ, Griffith J, Treilleux I, Goddard S, Davoust J, Kleijmeer M, Lebecque S: CD208/dendritic cell-lysosomal associated membrane protein is a marker of normal and transformed type II pneumocytes. Am J Pathol 2004, 164:861-871.

35. Debbabi H, Ghosh S, Kamath AB, Alt J, Demello DE, Dunsmore S, Behar SM: Primary type II alveolar epithelial cells present microbial antigens to antigen-specific CD4 ${ }^{+}$T cells. Am J Physiol Lung Cell Mol Physiol 2005, 289: L274-279.

36. Gereke M, Jung S, Buer J, Bruder D: Alveolar type II epithelial cells present antigen to CD4(+) T cells and induce Foxp3(+) regulatory T cells. Am J Respir Crit Care Med 2009, 179:344-355.

37. Wu Z, Hu T, Butter C, Kaiser P: Cloning and characterization of the chicken orthologue of dendritic cell-lysosomal associated membrane protein (DC-LAMP). Dev Comp Immunol 2010, 34:183-188.

38. Wilke S, Groebe L, Maffenbeier V, Jäger V, Gossen M, Josewski J, Duda A Polle L, Owens RJ, Wirth D, Heinz DW, van den Heuvel J, Büssow K: Streamlining homogeneous glycoprotein production for biophysical and structural applications by targeted cell line development. Plos One 2011, 6:e27829.

39. Wilke S, Krausze J, Gossen M, Groebe L, Jäger V, Gherardi E, van den Heuvel J, Büssow K: Glycoprotein production for structure analysis with stable, glycosylation mutant $\mathrm{CHO}$ cell lines established by fluorescenceactivated cell sorting. Protein Sci 2010, 19:1264-1271.

40. Krissinel $E$, Henrick $K$ : Inference of macromolecular assemblies from crystalline state. J Mol Biol 2007, 372:774-797.

41. Murzin AG, Brenner SE, Hubbard T, Chothia C: SCOP: a structural classification of proteins database for the investigation of sequences and structures. J Mol Biol 1995, 247:536-540.

42. Chan AW, Hutchinson EG, Harris D, Thornton JM: Identification classification, and analysis of beta-bulges in proteins. Protein Sci 1993 2:1574-1590.

43. Tremblay DM, Tegoni M, Spinelli S, Campanacci V, Blangy S, Huyghe C, Desmyter A, Labrie S, Moineau S, Cambillau C: Receptor-binding protein of Lactococcus lactis phages: identification and characterization of the saccharide receptor-binding site. J Bacteriol 2006, 188:2400-2410.

44. McMahon SA, Miller JL, Lawton JA, Kerkow DE, Hodes A, Marti-Renom MA Doulatov S, Narayanan E, Sali A, Miller JF, Ghosh P: The C-type lectin fold as an evolutionary solution for massive sequence variation. Nat Struct Mol Biol 2005, 12:886-892.

45. Jentoft N: Why are proteins O-glycosylated? Trends Biochem Sci 1990 15:291-294.

46. Eswar N, Webb B, Marti-Renom MA, Madhusudhan MS, Eramian D, Shen MY, Pieper U, Sali A: Comparative protein structure modeling using MODELLER. Curr Protoc Bioinformatics 2006, Chapter 5(Unit 5 6).

47. Bohne-Lang A, von der Lieth CW: GlyProt: in silico glycosylation of proteins. Nucleic Acids Res 2005, 33:W214-219. 
48. GLYCAM Web. [http://www.glycam.com].

49. Javadpour MM, Eilers M, Groesbeek M, Smith SO: Helix packing in polytopic membrane proteins: role of glycine in transmembrane helix association. Biophys J 1999, 77:1609-1618.

50. Demirel Ö, Jan I, Wolters D, Blanz J, Saftig P, Tampé R, Abele R: The lysosomal polypeptide transporter TAPL is stabilized by the interaction with LAMP-1 and LAMP-2. J Cell Sci 2012.

51. Schuske K, Palfreyman MT, Watanabe S, Jorgensen EM: UNC-46 is required for trafficking of the vesicular GABA transporter. Nat Neurosci 2007 . 10:846-853.

52. Griffiths $\mathrm{G}$, Back R, Marsh M: A quantitative analysis of the endocytic pathway in baby hamster kidney cells. J Cell Biol 1989, 109:2703-2720.

53. Griffiths G, Fuller SD, Back R, Hollinshead M, Pfeiffer S, Simons K: The dynamic nature of the Golgi complex. J Cell Biol 1989, 108:277-297.

54. Schröder BA, Wrocklage C, Hasilik A, Saftig P: The proteome of lysosomes. Proteomics 2010, 10:4053-4076.

55. Reitsma S, Slaaf D, Vink H, van Zandvoort M, oude Egbrink M: The endothelial glycocalyx: composition, functions, and visualization. Pflügers Arch 2007, 454:345-359.

56. Waterhouse AM, Procter JB, Martin DMA, Clamp M, Barton GJ: Jalview Version 2-a multiple sequence alignment editor and analysis workbench. Bioinformatics 2009, 25:1189-1191.

57. Katoh $\mathrm{K}$, Asimenos $\mathrm{G}$, Toh $\mathrm{H}$ : Multiple alignment of DNA sequences with MAFFT. Methods Mol Biol 2009, 537:39-64.

58. Guex N, Peitsch MC: SWISS-MODEL and the Swiss-Pdb Viewer: An environment for comparative protein modeling. Electrophoresis 1997 18:2714-2723.

59. Carlsson SR, Lycksell PO, Fukuda M: Assignment of O-glycan attachment sites to the hinge-like regions of human lysosomal membrane glycoproteins lamp-1 and lamp-2. Arch Biochem Biophys 1993, 304:65-73.

60. Case DA, Darden TA, Cheatham TE III, Simmerling CL, Wang J, Duke RE, Luo R, Walker RC, Zhang W, Merz KM, Roberts B, Wang B, Hayik S, Roitberg A, Seabra G, Kolossvary I, Wong FK, Paesani F, Vanicek J, Liu J, Wu X, Brozell SR, Steinbrecher T, Gohlke H, Cai Q, Ye X, Wang J, Hsieh M-J, Cui G, Roe DR, et al: AMBER11. San Francisco: University of California; 2010.

61. Kirschner KN, Yongye AB, Tschampel SM, Gonzalez-Outeirino J, Daniels CR, Foley BL, Woods RJ: GLYCAM06: a generalizable biomolecular force field. Carbohydrates. J Comput Chem 2008, 29:622-655.

62. Kabsch W: XDS. Acta Crystallogr D 2010, 66:125-132.

63. Matthews BW: Solvent content of protein crystals. J Mol Biol 1968, 33:491-497.

64. Vagin A, Teplyakov A: MOLREP: An automated programm for molecular replacement. J Appl Crystallogr 1997, 30:1022-1025.

65. Adams PD, Afonine PV, Bunkoczi G, Chen VB, Davis IW, Echols N, Headd Jر, Hung LW, Kapral GJ, Grosse-Kunstleve RW, McCoy AJ, Moriarty NW, Oeffner R, Read RJ, Richardson DC, Richardson JS, Terwilliger TC, Zwart PH: PHENIX: a comprehensive Python-based system for macromolecular structure solution. Acta Crystallogr D 2010, 66:213-221.

66. McCoy AJ, Grosse-Kunstleve RW, Adams PD, Winn MD, Storoni LC, Read RJ: Phaser crystallographic software. J Appl Crystallogr 2007, 40:658-674.

67. Emsley P, Cowtan K: Coot: model-building tools for molecular graphics. Acta Crystallogr D 2004, 60:2126-2132.

68. Pettersen EF, Goddard TD, Huang CC, Couch GS, Greenblatt DM, Meng EC, Ferrin TE: UCSF Chimera-a visualization system for exploratory research and analysis. J Comput Chem 2004, 25:1605-1612.

69. Kabsch W, Sander C: Dictionary of protein secondary structure: pattern recognition of hydrogen-bonded and geometrical features. Biopolymers 1983, 22:2577-2637.

70. Ho BK, Gruswitz F: HOLLOW: generating accurate representations of channel and interior surfaces in molecular structures. BMC Struct Biol 2008, 8:49.

doi:10.1186/1741-7007-10-62

Cite this article as: Wilke et al:: Crystal structure of the conserved domain of the DC lysosomal associated membrane protein: implications for the lysosomal glycocalyx. BMC Biology 2012 10:62

\section{Submit your next manuscript to BioMed Central and take full advantage of:}

- Convenient online submission

- Thorough peer review

- No space constraints or color figure charges

- Immediate publication on acceptance

- Inclusion in PubMed, CAS, Scopus and Google Scholar

- Research which is freely available for redistribution

Submit your manuscript at www.biomedcentral.com/submit 